\title{
Uma análise sobre a prática pedagógica do professor de educação física*
}

\section{An analysis on the pedagogical practice of the professor of physical education}

Ayane Katarinne Santos da Costa ${ }^{1}$ Arthur José Medeiros de Almeida²
Recebido em: 17/09/2016. Aprovado em: 18/01/2017.

1 Licenciada em Educação Física - Centro Universitário de Brasília - UniCEUB - Brasília, Brasil. ayane.any@hotmail.com.

2 Professor Doutor - Centro Universitário de Brasília - UniCEUB, Brasília, Brasil. arthur_ edf@hotmail.com.

\section{Resumo}

Na década de 1980, surgiram concepções pedagógicas na área da Educação Física que propiciaram diferentes maneiras de ensinar as manifestações da cultura corporal na escola. No entanto, existe um número reduzido de pesquisas que analisam a influência dessas concepções na Educação de Jovens e Adultos - EJA. Nesse sentido, o objetivo deste trabalho foi analisar a prática pedagógica do professor de Educação Física que atua na Educação de Jovens e Adultos, considerando o conhecimento do professor sobre as concepções pedagógicas. Trata-se de um estudo de caso, com abordagem qualitativa em que se utilizou como técnicas de pesquisa a entrevista estruturada e observação sistemática de aulas com o registro em diário de campo. Notou-se que o professor fundamentou suas aulas nas concepções críticas de ensino da Educação Física, porém sem distinção entre elas.

Palavras-chave: Educação Física. Escola. Educação. Saúde.

\begin{abstract}
In the Decade of 1980 the emergence of new teaching conceptions signaled the emergence of pedagogical conceptions of physical education for to teach body culture in school. However, there is a limited number of surveys that analyze the influence of these conceptions in adult and youth education. In this sense, In this sense, the objective of this work was analyze the pedagogical practice of the physical education teacher who acts in adult and youth education whereas the teacher's knowledge about pedagogical concepts and thus understand how he takes effect. This was case study with a qualitative approach and used structured interview and systematic observation of lessons from field journal. The teacher divided the contents of the bimester observed in two themes, which are: physical conditioning and futsal. With respect to its pedagogical method, he couldn't define what design is built to teach their classes however it is believed that it is possible to identify the fundamentals that drive their pedagogical practice. It was noted that the teacher he based his lessons in critical conceptions of teaching of physical education, without distinction among them.
\end{abstract}

Keywords: Physical Education. School. Education. Health. 


\section{Introdução}

A Educação Física, no contexto histórico brasileiro, esteve ligada às instituições militares, em que um dos principais objetivos era uma preparação para a defesa da pátria, bem como às instituições médicas, onde o objetivo era a educação do corpo (físico saudável e equilibrado organicamente). Essas características foram importantes para a legitimação da disciplina na escola (BRASIL, 1997).

Na década de 1970, a Educação Física na escola voltou-se para o ensino das técnicas esportivas. Galvão (2002) retrata que o tipo de formação docente oferecido nessa década não oportunizou ao professor reconhecer seus alunos como indivíduos e cidadãos, já que a preocupação girava em torno de uma prática esportiva tecnicista visando à competição e à performance.

A partir da década de 1980, a Educação Física começou a ampliar seu rol de conteúdos e passou a abordar o esporte, a ginástica, os jogos, as lutas e a dança relacionando-os a temas relevantes no contexto social brasileiro. Dentre os temas que devem ser abordados por essa disciplina na escola, destacam-se o conhecimento sobre o corpo, a saúde e os exercícios físicos na contemporaneidade (BRASIL, 2006).

Para que a Educação Física contribua para a formação integral dos alunos, os professores precisam fazer uma relação entre a teoria e a prática, fundamentando a sua prática pedagógica em uma concepção de ensino (BETTI; ZULIANI; 2002). Entende-se, portanto, que as concepções pedagógicas da Educação Física fundamentam a prática pedagógica do professor na escola. Barbieri, Porelli e Mello (2008) acreditam que o surgimento de diferentes concepções a partir da década de 1980 veio salientar o avanço, pois cada uma trouxe consigo particularidades de distintas áreas do conhecimento, servindo de base para o desenvolvimento dessa disciplina no contexto escolar.

Bracht (1999) resume algumas concepções para que se possa ter um melhor e mais fácil entendimento. Inicialmente, o autor apresenta a abordagem desenvolvimentista, em que seu objetivo central é oportunizar a criança a experimentar os movimentos de forma a garantir o desenvolvimento das habilidades motoras com base em um padrão de normalidade. Cabe ressaltar, ainda, a ideia de Darido (2001) que descreve que nessa concepção o movimento é o principal meio e fim da Educação Físi- ca, justificando a especificidade do seu objeto. Privilegia a aprendizagem do movimento, porém considera que o processo de aprendizagem envolve o desenvolvimento dos aspectos cognitivos e afetivos.

Seguindo com sua explicação, Bracht (1999) apresenta a psicomotricidade como uma abordagem em que o movimento é um instrumento para o desenvolvimento integral do estudante, porém não considerando as formas culturais do movimentar-se humano como um saber a ser transmitido pela escola. Darido (2001) explicita que nessa abordagem a preocupação da Educação Física é com o desenvolvimento da criança de forma integral, atendendo as suas necessidades cognitivas, afetivas e motoras.

A crítico-superadora, segundo Bracht (1999), propõe a cultura corporal como principal objeto da Educação Física, que se concretiza em esportes, jogos, lutas, ginástica, danças ou mímicas. Além disso, sistematiza o conhecimento da Educação Física em ciclos, considerando uma forma historicizada, possibilitando a compreensão dos aspectos contraditórios do movimento humano. Segundo o Coletivo de Autores (1992), essa abordagem não trata os elementos técnicos e táticos como exclusivos e únicos conteúdos da aprendizagem, porém consideram necessário o domínio de tais elementos. Além disso, essa perspectiva trabalha com um espaço intencionalmente organizado, possibilitando, assim, um direcionamento da compreensão pelos alunos do conhecimento específico da Educação Física e dos diversos aspectos das suas práticas na realidade social.

Por fim, Bracht (1999) contextualiza a abordagem crítico-emancipatória, em que esta tem o intuito de formar um sujeito crítico e autônomo, que estabeleça uma forma de comunicação com o mundo. Oliveira e Ribas (2010) acrescentam que essa abordagem proporciona para os alunos um entendimento de que o esporte não é algo natural e sim uma invenção social, sendo assim, acaba por reproduzir as ideologias dessa prática social, alcançando, dessa maneira, um melhor entendimento sobre a realidade onde essa manifestação se insere.

Há alguns anos, a EJA era compreendida como um processo de incentivo à leitura e à escrita, sem levar em consideração questões como o conhecimento que os alunos carregavam consigo e de suas vidas cotidianas. Porém, notaram-se várias razões que levavam esses estudantes à escola, tais como: exigências econômicas, tecnológicas e a competitividade do mercado de trabalho. Isso proporcionou um novo pensar sobre a educação de 
jovens e adultos (STRELHOW, 2010), inclusive na disciplina Educação Física, já que esta, também, é ofertada na EJA. Assim, o objetivo deste trabalho é fazer uma análise sobre a prática pedagógica do professor de Educação Física na Educação de Jovens e Adultos (EJA), considerando o seu conhecimento sobre as concepções pedagógicas e dessa maneira compreender como ele planeja suas aulas, visando alcançar os objetivos da Educação Física.

\section{Materiais e Métodos}

\subsection{Amostra}

Tratou-se de estudo de caso, com abordagem qualitativa, que buscou analisar a prática pedagógica de um professor de Educação Física de uma escola da rede pública de ensino do Distrito Federal. Foram observadas aulas de uma turma do $1^{\circ}$ ano do ensino médio da Educação de Jovens e Adultos realizadas no turno noturno, conforme se apresenta no tipo de estudo escolhido.

$\mathrm{O}$ estudo de caso visa à investigação de um caso específico, bem delimitado, contextualizado em tempo e lugar para que se possa realizar uma busca circunstanciada de informações, ou seja, tem o seu objeto de estudo o interesse em casos individuais (VENTURA, 2007).

A presente pesquisa foi submetida ao Comitê de Ética em Pesquisa do UniCEUB, por meio da Plataforma Brasil, sendo esta autorizada sob o número CAEE 48335015.3.0000.0023.

\subsection{Métodos}

Para a realização deste estudo realizou-se pesquisa bibliográfica, entrevista estruturada e observação sistemática de aulas com o registro em diário de campo, visando obter resultados mais concretos quanto à proposta pedagógica aplicada pelo professor de Educação Física e sua didática em suas aulas.

Na entrevista estruturada, o pesquisador segue um roteiro previamente elaborado e deve ser seguida, exatamente, conforme esse roteiro, sem liberdade de adaptar as questões estabelecidas. Já a escolha da observação sistemática fez-se pelo fato de que o observador deve saber o que procura e o que carece de importância em determinada situação. Nesse processo, o pesquisador deve ser objetivo, reconhecer possíveis erros e ser neutro em relação a sua opinião sobre o que vê e/ou recolhe (MARCONI; LAKATOS, 2003).

A pesquisa teve a duração de dois meses, em que se observaram 08 aulas que compõem um bimestre letivo de uma turma específica do Ensino Médio, escolhida por conter um maior número de alunos. A entrevista com o professor regente ocorreu no segundo dia de observação, sendo esta realizada anterior ao início da aula.

\section{Resultados}

O professor de Educação Física participante do estudo atua na Secretaria de Educação do Distrito Federal há 22 anos e na Educação de Jovens e Adultos (EJA) há 9 anos. Em conversas com o professor regente antes e depois das aulas, este comentou que os professores não estão preparados a lidar com o público da EJA, pois esses estudantes possuem especificidades que muitas vezes não são apresentadas nos cursos de formação profissional.

Ao falar sobre as dificuldades de trabalhar na EJA, o docente afirmou que:

É difícil porque hoje a EJA, ela está se transformando em uma tábua de salvação para o aluno que não encontra progresso no ensino regular e o tempo passa, os 'caras' vão ficando e as correções do fluxo não vão dando muitos resultados e acaba que o 'cara' completa 18 anos e continua no primeiro ano e acaba que entra no mercado de trabalho e tem que estudar a noite [...]. Mas ainda é, em grande parte, o trabalhador, a pessoa que não teve oportunidade de estudar no período regular e vem recuperar o tempo perdido na EJA. Mas dificuldade mesmo não tem tanta assim não, é engrandecedor trabalhar com adulto, a gente se enriquece e aprende muito. A gente tem muito o que aprender com eles, são pessoas experientes.

Outro aspecto relevante são as características dos estudantes que, em sua maior parte, são trabalhadores que deixaram de estudar durante alguns anos. Além disso, esses estudantes podem solicitar dispensa das aulas de Educação Física, pois a Lei no 10.793/2003 assegura a prática facultativa ao estudante que cumpra jornada de trabalho igual ou superior a seis horas diárias (BRASIL, 2003).

O professor regente da Educação Física afirmou utilizar o mesmo plano de curso há pelo menos dois anos para desenvolver o trabalho pedagógico na instituição de ensino e considera que a escola pesquisada não se preocupa em verificar se este é efetivado. Quanto a atingir os objetivos propostos em seu plano de ensino, o professor alegou que nem sempre conseguia alcançar os resultados pretendidos, principalmente pela falta de interesse e de 
participação da turma nas aulas, mesmo quando se tratava da própria saúde dos estudantes.

\subsection{0 conteúdo}

O professor dividiu o conteúdo do bimestre observado em dois temas, os quais são: (1) condicionamento físico e saúde, (2) futsal. Durante a observação, sobre o tema condicionamento físico e saúde, foi apresentada sua definição, a maneira pela qual mensura-se ter um condicionamento bom ou ruim. Complementarmente, associou assuntos como sedentarismo, a importância da prática de atividades físicas para a saúde e o uso de anabolizantes e suplementação.

Todavia, nas aulas observadas foi possível identificar que poucos estudantes da turma o questionaram sobre a questão de prevenção e tratamento de doenças, reconhecendo o professor de Educação Física, muitas vezes, como um profissional da saúde. O professor explicava com clareza e profissionalismo aos alunos que eles deveriam procurar profissionais específicos para diagnóstico e tratamentos adequados para tais questões que seu intuído era promover a compreensão sobre a saúde.

É possível analisar a afirmação acima nas duas primeiras aulas observadas, quando o professor ministrou aulas sobre o condicionamento físico, sedentarismo e a atividade física na prevenção de doenças. Este questionou a turma sobre a prática de atividade física e 65\% dos alunos consideravam-se ativos e 35\% sedentários. Diante desse quadro, o professor ensinou a turma a utilizar o cálculo de Batimentos por Minuto da Frequência Cardíaca, bem como, o teste de Cooper (1968) para mensurar o nível de condicionamento físico dos estudantes.

Com relação ao futsal, abordaram-se aspectos do seu contexto histórico, as regras, sua popularidade e questões como não ser um esporte olímpico. Além disso, o professor comparou outros esportes ao futsal, como o futebol, society e a "pelada" de fim de semana, pois os alunos não compreendiam tais diferenças e suas especificidades.

\subsection{Metodologia de aulas: teóricas, práticas e teóri- co-práticas}

Ao questionar o professor sobre o seu método pedagógico, este afirmou que:

Eu acho que meu método pedagógico ele é aberto, amplo, democrático e acho que eu tenho um retorno da minha maneira de atuar. Eu me baseio bastante no currículo, eu uso ele bastante como base, mas eu também faço as minhas inserções e a minha experiência também faz com que eu possa estar fazendo minhas modificações.

No entanto, ao ser questionado sobre as concepções de ensino da Educação Física, ele não soube falar sobre elas e nem sobre qual ele se baseia para ministrar suas aulas. Porém, acredita-se que seja possível identificar os fundamentos que orientam a sua prática pedagógica.

Ao falar sobre os temas condicionamento físico e saúde, o professor buscou abordar o contexto histórico chegando até a atualidade, mostrando, assim, as constantes mudanças que se tem em termos e indicações de práticas corporais.

O professor estimulou bastante a participação dos alunos em suas aulas, para que eles pudessem fazer questionamentos sobre o tema trabalhado, seja em forma de perguntas ou citando exemplos próprios ou de parentes e amigos. A sua forma de diálogo foi bastante descontraída, fazendo com que os alunos interagissem mais. Portanto, um aspecto relevante nesse método é a relação professor-aluno.

Outro aspecto importante quanto à metodologia do professor foi a tentativa de reconhecer a realidade socioeducativa de seus estudantes, sabendo que muitos não conseguem compreender e interpretar, de forma adequada, o conteúdo ministrado devido às situações socioeconômicas em que se encontravam..

Ao falar sobre o futsal, o professor abordou o seu contexto histórico, regras e conhecimentos sobre a quadra poliesportiva para essa modalidade. Ao propor um jogo de futsal, uma aula prática, os alunos, em sua maioria, preferiram ter aulas, apenas, teóricas, pois alegam chegar cansados do trabalho ou não terem idade para esse tipo de prática.

Pôde-se notar, também, que as mulheres não compreenderam termos e regras utilizados no futsal, principalmente porque acreditam que esse esporte é voltado, apenas, para o sexo masculino, reconhecendo, assim, que esse conhecimento para elas não fosse necessário.

\subsection{Avaliação}

O método de avaliação adotado pelo professor tratou-se de avaliações objetivas de múltipla escolha, cada prova contendo o número de 10 (dez) questões. No entanto, ele permitia que os alunos consultassem suas apostilas durante as provas.

Quando entrevistado sobre quais as formas e os 
métodos de avaliação que utiliza na EJA, o professor respondeu:

Prova teórica, eu explano o assunto, estabeleço o conteúdo e eles tem a apostila, eles leem, as aulas são explicitas, a gente vai colocando em sala de aula o assunto. Quando há um tempo em que eles se expõem a prática, porque o aluno do EJA não é que ele está sempre disponível para a prática, mas sempre que tem a prática a gente abre para jogos, aspecto lúdico, brincadeiras e diversões que possa levar o aluno a se divertir, curtir, se descontrair, no dia a dia o aluno já vem de um dia de trabalho, já vem de um dia de luta 'né.

Notou-se que, com a oportunidade de consultar a apostila, 90\% dos alunos se quer tentaram responder às questões com base em conhecimentos adquiridos durante o bimestre, o que pode significar que eles não buscavam ler a apostila em seus lares ou se quer a reconhecem como auxílio, mas sim como uma atividade de sala com consulta. Os outros $10 \%$ leram a prova e tentaram respondê-la sem qualquer consulta, mas, quando ficavam em dúvida, recorriam ao uso da apostila, reconhecendo-a como um auxílio apenas quando necessário.

\section{Discussão}

No Brasil, os analfabetos sofreram muitos preconceitos por não terem conhecimento escolar, eram discriminados e considerados incapazes não apenas socialmente, mas, psicologicamente, também. Por essa condição, não tinham direitos econômicos, políticos e jurídicos, acesso ao voto e muitas vezes eram explorados em seus trabalhos por não terem conhecimento e cultura (COLAVITTO; ARRUDA, 2014).

A Educação de Jovens e Adultos ao longo de sua trajetória foi tema de política educacional, no entanto, apenas, na década de 1940, a EJA obteve maior interesse político com ações mais concretas. Ainda nessa década, a Campanha de 1947 chamou atenção para as questões de um campo de reflexão pedagógica em torno do analfabetismo e suas consequências psicossociais (DI PIERRO; JOIA; RIBEIRO, 2001).

A Constituição Federal de 1988 garante para todos cidadãos brasileiros o direito à educação, porém, só em 1996, a EJA foi assegurada para aqueles que não puderam ou não tiveram oportunidade de concluir o ensino fundamental e/ou ensino médio no ensino regular. Conforme o Artigo 37 da Lei de Diretrizes e Bases da Educação (lei no 9.394/96), a Educação de Jovens e Adultos é "destinada àqueles que não tiveram acesso ou continuidade de estudos no ensino fundamental e médio na idade própria" (BRASIL, 1996).

De acordo com Paiva, Machado e Ireland (2007), não há estatísticas confiáveis sobre o público que procura pela EJA. No entanto, nota-se que tem sido um público bastante heterogêneo, pois o paradigma vem mudando em termos de idade, expectativa e comportamentos. Não se trata, somente, de alunos adultos, mas também de adolescentes que podem vir de um contexto histórico de exclusão, ora pela impossibilidade de acesso à educação, ora pela sua expulsão da educação regular, e têm a necessidade de retornar aos estudos.

Um dos problemas enfrentados pela EJA e que merece destaque é a falta de um corpo docente habilitado e qualificado para essa modalidade de ensino, pois os cursos de formação para o magistério não contemplam a especificidade da área, além das possibilidades de aperfeiçoamento nessa modalidade ser bastante reduzida (PAIVA; MACHADO; IRELAND, 2007).

Foi possível observar dois aspectos fundamentais quanto às dificuldades que o professor enfrenta na EJA: a primeira é a falta de recursos e de materiais, que são bem precários na escola; a segunda é a falta de motivação e interesse dos alunos pela disciplina.

Conforme apresentado nos resultados deste estudo, o professor buscou fazer uma contextualização sobre os temas trabalhados, o que foi possível verificar na aula sobre o futsal. Para Darido (2003), a concepção crítico-superadora não se preocupa, apenas, com questões sobre como ensinar, mas também com a maneira pela qual adquirimos esses conhecimentos. Considera-se a questão da contextualização dos fatos e do resgate histórico, ferramentas essenciais para a prática pedagógica e formação de conhecimento.

Além disso, para o Coletivo de Autores (1992), é necessário compreender as relações de interdependência do que está sendo ensinado com grandes problemas sociopolíticos atuais, possibilitando, assim, ao aluno entender a realidade social, interpretando-a e explicando-a com base em seus interesses de classe social. Nessa perspectiva, a escola deve formar um cidadão crítico e consciente da realidade social em que vive, para que, assim, conscientemente, ele possa intervir na direção dos seus interesses de classe.

Em suas aulas, o professor, sempre, buscou pro- 
porcionar a participação dos alunos, fazendo com que eles fizessem parte do processo pedagógico proposto pelo professor. Kunz (1994) aponta uma característica fundamental da relação professor-aluno na concepção crítico-emancipatória, em que se deve priorizar o diálogo e proporcionar maior abertura durante o transcorrer das aulas, fazendo com que os educandos tenham maior participação no processo pedagógico.

Pode-se, ainda, citar uma influência do ensino aberto ao comparar a metodologia de ensino do professor com os fundamentos que regem essa concepção. $\mathrm{O}$ professor, ao utilizar a concepção de ensino aberto, teve a intenção de ser um mediador entre o conhecimento científico e os saberes dos estudantes. Nessa concepção de ensino, defende-se um ensino centralizado nas experiências dos alunos, ou seja, os alunos participam das decisões em relação às aulas, aos objetivos e conteúdos a serem trabalhados no processo de ensino e aprendizagem.

Portanto, nota-se que o professor fundamentou suas aulas nas concepções críticas de ensino da Educação Física, porém, sem distinção entre a concepção crítico-superadora e crítico-emancipatória, demonstrando um ecletismo teórico para direcionar o seu trabalho de acordo com a sua realidade. Pode-se notar essa afirmativa ao compararmos as características das aulas do professor com as características que fundamentam as duas concepções críticas.

A Educação Física tem passado por várias modificações durante os últimos anos e isso é algo engrandecedor para a área. No entanto, a disciplina na escola não tem recebido o reconhecimento necessário para que essas mudanças influenciem a vida e a maneira de olhar dos alunos e colegas de outras áreas de ensino.

O que foi possível notar nas aulas observadas é que há um desinteresse dos estudantes da EJA pelos temas propostos na disciplina Educação Física, principalmente sobre a prática de atividade física e saúde no contexto educativo, o que pode influenciar bastante o método e atitudes do professor ao planejar o seu trabalho.

Outro ponto bastante importante e que deve ser considerado é como o professor se preparou para as aulas e para se reconhecer como um docente responsável por transformações sociais. Nesse sentido, o professor utili- ções críticas de ensino, porém, com uma especificidade própria. Além disso, é necessário reconhecer, também, que os cursos de formação de professores não estão preparando os futuros docentes para lidar com o público heterogêneo da EJA.

Após considerar pontos importantes como esses, entende-se que a escolha de uma concepção pedagógica se faz fundamental para a prática pedagógica do professor, pois não é possível o professor entrar em uma sala de aula sem planejamento e fundamentação, e, desse modo, querer dar uma aula excelente e fazer a diferença na realidade de seus alunos, principalmente em relação ao público da EJA, que já vem de uma realidade de exclusão, descaso e falta de oportunidades.

Contudo, entende-se a necessidade da realização de mais estudos sobre a prática pedagógica de professores de Educação Física que atuam na Educação de Jovens e Adultos, pois o presente artigo apresenta a análise de um caso particular de um contexto específico. Desse modo, entende-se que o conhecimento produzido pode ser socializado e contribuir para a formação de professores da área para atuarem de forma qualificada nessa modalidade de ensino no Brasil.

\section{Referências}

BARBIERI, A. F.; PORELlI, A. B. G.; MELLO, R. A. Abordagens, concepções e perspectivas de Educação Física quanto à metodologia de ensino nos trabalhos publicados na Revista Brasileira de Ciências do Esporte (RBCE) em 2009. Motrivivência, Florianópolis, v. 20, n. 31, p. 223-240, dez. 2008. zou-se de métodos pedagógicos enfatizados por concep-
BETTI, M.; ZULIANI, L. R. Educação Física escolar: uma proposta de diretrizes pedagógicas. Revista Mackenzie de Educação Física e Esporte, São Paulo, v. 1, n. 1, p. 73 81, jan./dez. 2002.

BRACHT, V. A constituição das teorias pedagógicas da educação física. Cadernos Cedes, Campinas, v. 19 , n. 48 , p. $69-88$, ago. 1999. doi: 10.1590/S010132621999000100005

BRACHT, V. et al. A prática pedagógica em educação física: a mudança a partir da pesquisa-ação. Revista Brasileira de Ciências do Esporte, Campinas, v. 23, n. 2, p. 9-29, jan. 2002.

BRASIL. Ministério da Educação. Lei no 9.394, de 20 de dezembro de 1996. Disponível em: <http://www.planalto.gov.br/ccivil_03/leis/L9394.htm>. Acesso em: 15 mar. 2017. 
BRASIL. Ministério da Educação. Lei no 10.793, de 1 de dezembro de 2003. Disponível em: <http://www.planalto. gov.br/ccivil_03/leis/2003/L10.793.htm >. Acesso: 15 mar. 2017.

BRASIL. Ministério da Educação. Secretaria de Educação Básica. Orientações curriculares para o ensino médio Linguagens, códigos e suas tecnologias. Brasília: Ministério da Educação, 2006.

COLAVITTO, N. B; ARRUDA, A. L. M. M. Educação de Jovens e Adultos (eja): a importância da alfabetização. Revista Eletrônica Saberes da Educação, São Roque, v. 5, n. 1, p. 1-28, jan./dez. 2014.

METODOLOGIA do ensino de Educação Física. São Paulo: Cortez, 1992.

DARIDO, S. C. Educação Física na escola: questões e reflexões. Rio de Janeiro: Guanabara Koogan, 2003.

DARIDO, S. C. Os conteúdos da educação física escolar: influências, tendências, dificuldades e possibilidades. Perspectivas em Educação Física Escolar, Niterói, v. 2, n. 1 (suplemento), p. 5-26, dez. 2001.

DI PIERRO, M. C.; JOIA, O.; RIBEIRO, V. M. Visões da educação de jovens e adultos no Brasil. Cadernos Cedes, Campinas, v. 21, n. 55, p. 58-77, nov. 2001.
GALVÃO, Z. Educação Física escolar: a prática do bom professor. Revista Mackenzie de Educação Física e Esporte, São Paulo, v. 1, n. 1, p. 65-72, jan./dez. 2002.

KUNZ, E. Transformação didático-pedagógica do esporte. Ijuí: Unijuí, 1994.

MARCONI, M. A; LAKATOS, E. M. Fundamentos de metodologia científica. 5. ed. São Paulo: Atlas, 2003.

OLIVEIRA, G. T; RIBAS, J. F. M. Articulações da praxiologia motriz com a Concepção Crítico-Emancipatória. Movimento, Porto Alegre, v. 16, n. 1, p. 131-148, jan./ mar., 2010.

PAIVA, J; MACHADO, M. M; IRELAND, T. Educação de Jovens e Adultos: uma memória contemporânea, 1996-2004. Brasília: Secretaria de Educação Continuada, Alfabetização e Diversidade do Ministério da Educação: Organização das Nações Unidas para a Educação, a Ciência e a Cultura, 2007.

STRELHOW, T. B. Breve história sobre a educação de jovens e adultos no Brasil. Revista HISTEDBR On-line, Campinas, v. 10, n. 38, p. 49-59, jun. 2010.

VENTURA, M. M. O estudo de caso como modalidade de pesquisa. Revista da SOCERJ, Rio de Janeiro, v. 20, n. 5, p. 383-386, set./out. 2007. 